\title{
Thioredoxin-1 inhibitor, 1-methylpropyl 2-imidazolyl disulfide, inhibits the growth, migration and invasion of colorectal cancer cell lines
}

\author{
FULE WANG $^{1 *}$, FEIYAN LIN ${ }^{1 *}$, PEILI ZHANG ${ }^{1}$, WUHUA NI $^{2}$, LAIXI BI $^{3}$, JIANBO WU $^{1}$ and LEI JIANG ${ }^{1}$ \\ ${ }^{1}$ Laboratory of Internal Medicine, ${ }^{2}$ Reproductive Medicine Center and ${ }^{3}$ Department of Hematology, \\ The First Affiliated Hospital of Wenzhou Medical University, Wenzhou, Zhejiang 325000, P.R. China
}

Received July 30, 2014; Accepted November 11, 2014

DOI: $10.3892 /$ or.2014.3652

\begin{abstract}
Methylpropyl 2-imidazolyl disulfide (PX-12) has been proposed as an inhibitor of thioredoxin-1 (Trx-1) with antitumor activity. However, the antitumor activity of the Trx-1 redox signaling inhibitor PX-12 on colorectal cancer is still obscure. In the present study, we showed that PX-12 inhibited the growth of colorectal cancer DLD-1 and SW620 cells in a dose- and timedependent manner. Further analysis demonstrated that PX-12 reduced cell colony formation and induced a $\mathrm{G} 2 / \mathrm{M}$ phase arrest of the cell cycle. In addition, PX-12 treatment induced apoptosis, as observed by the increased number of Annexin V-positive cells and increased activation of caspase-3. Notably, a low dose of PX-12 inhibited colorectal cancer cell migration and invasion. Treatment of cancer cells with PX-12 reduced NOX1, CDH17 and S100A4 mRNA expression, and increased KLF17 mRNA expression. Moreover, PX-12 decreased S100A4 protein expression in the colorectal cancer cells. Collectively, the present study demonstrates the antitumor effects and therapeutic potential of $\mathrm{PX}-12$ in colorectal cancer.
\end{abstract}

\section{Introduction}

Colorectal cancer is one of the leading causes of cancer-related mortality in most industrialized nations (1), and the effectiveness of conventional treatments for colorectal cancer is limited. Despite the fact that advances in the adjuvant treatment of colorectal cancer have been achieved for patients with lymph node-positive disease $(2,3)$, the risk of recurrence is significantly high. Hence,

Correspondence to: Dr Lei Jiang, Laboratory of Internal Medicine, The First Affiliated Hospital of Wenzhou Medical University, Wenzhou, Zhejiang 325000, P.R. China

E-mail: jiangleistone79@163.com

Dr Wuhua Ni, Reproductive Medicine Center, The First Affiliated Hospital of Wenzhou Medical University, Wenzhou, Zhejiang 325000, P.R. China

E-mail: niwuhua228@163.com

*Contributed equally

Key words: PX-12, colorectal cancer, antitumor activity, thioredoxin-1 extensive research has been conducted to find an effective adjuvant therapy for colorectal cancer (4), such as non-steroidal anti-inflammatory drugs, immunotherapy and gene therapy (5).

Thioredoxin (Trx) and thioredoxin reductase 1 (TR1) are among the major redox regulators in mammalian cells and control many cellular processes, including proliferation, defense against oxidative stress and apoptosis $(6,7)$. Thioredoxin-1 (Trx-1), an ubiquitously expressed low-molecular-weight redox protein, is overexpressed in several types of human cancers (8-10) and has multiple effects in cells that include transactivating activity of a number of redox-sensitive transcription factors $(11,12)$, and the regulation of DNA binding (13). Trx-1 has been shown to play a critical role in a series of human diseases including cancer of the cervix, pancreas, lung, colorectal and squamous cell cancer (8-10,14-16). Trx-1-transfected cells exhibit increased colony formation and cell growth in soft agar (17). Retrospective analyses in colorectal cancer indicate that increased expression of Trx-1 in cancer cells may be an independent prognostic factor (10).

1-Methylpropyl 2-imidazolyl disulfide (PX-12) is a potent inhibitor of Trx-1 by irreversible thioalkylation of $\mathrm{Cys}^{73}$ which lies outside the conserved redox catalytic site of Trx-1, causing inhibition of Trx-dependent cell growth $(18,19)$. PX-12 has been shown to have in vivo antitumor activity against human tumor xenografts including HT-29 colon cancer in SCID mice and has been tested in a phase I clinical trial in patients (20). In the present study, we investigated the antitumor effects of the Trx-1 redox signaling inhibitor PX-12 on colorectal cancer in vitro, including induction of apoptosis, growth arrest, inhibition of cell migration and invasion.

\section{Materials and methods}

Cell lines and cell culture. Two colorectal cancer cell lines SW620 and DLD-1 were used in the present study. They were cultured in Dulbecco's modified Eagle's medium (DMEM) supplemented with $10 \%$ fetal bovine serum (FBS; Invitrogen, Carlsbad, CA, USA), $100 \mu \mathrm{g} / \mathrm{ml}$ streptomycin and $100 \mathrm{U} / \mathrm{ml}$ penicillin in a humidified $5 \% \mathrm{CO}_{2}$ incubator at $37^{\circ} \mathrm{C}$.

Cell viability and colony formation assays. Absorbance of 3-(4,5-dimethylthiazol-2-yl)-2,5-diphenyltetrazolium bromide 
Table I. Primers for the NOX1, CDH17, KLF17, S100P, S100A4 and GAPDH genes.

\begin{tabular}{lll}
\hline Gene name & \multicolumn{1}{c}{ Forward primer } & \multicolumn{1}{c}{ Reverse primer } \\
\hline NOX1 & 5'-GGATGATCGTGACTCCCACT-3' & 5'-TTTGGATGGGTGCATAACAA-3' \\
CDH17 & 5'-GACAATCGACCCACGTTTCT-3' & 5'-GCTCCCGTTTTGTTGTTGAT-3' \\
KLF17 & 5'-CTCCATGGCTCAGATGTTGC-3' & 5'-TAGTTGCAGCAGTAAGGCCT-3' \\
S100P & 5'-AAGGTGCTGATGGAGAAGGA-3' & 5'-ACTTGTGACAGGCAGACGTG-3' \\
S100A4 & 5'-GGTGTCCACCTTCCACAAGT-3' & 5'-GCTGTCCAAGTTGCTCATCA-3' \\
GAPDH & 5'-CCAGCCGAGCCACATCGCTC-3' & 5'-ATGAGCCCCAGCCTTCTCCAT-3'
\end{tabular}

(MTT; Sigma-Aldrich) in living cells was measured to determine the effect of PX-12 on cell viability. Briefly, $1 \times 10^{4}$ cells/ well were seeded in 96-well plates and exposed to the designated concentrations of PX-12 for the indicated times, MTT solution was added to each well. After the incubating time $(4 \mathrm{~h}$ at $37^{\circ} \mathrm{C}$ ) was completed, the medium was withdrawn from the plates and $200 \mu \mathrm{l}$ DMSO was added to each well to solubilize the formazan crystals. The optical density was measured at $490 \mathrm{~nm}$ using a Universal Microplate Reader (ELx800; BioTek Instruments, Inc., Winooski, VT, USA).

For the colony formation assay, 5,000 cells were seeded into a $10-\mathrm{cm}$ culture dish and incubated at $37^{\circ} \mathrm{C}$ in a humidified $5 \%$ $\mathrm{CO}_{2}$ incubator for 14 days to form colonies, which were then stained with Coomassie blue. The rate of colony formation was calculated with the following equation: Colony formation rate $=($ number of colonies/number of seeded cells) $\times 100 \%$.

Cell cycle analysis. Cell cycle analysis was performed using propidium iodide (PI) $(E x / E m=488 / 617 \mathrm{~nm}$; Sigma-Aldrich) staining. Briefly, $2 \times 10^{5}$ cells/well in 6 -well plates were treated with $5 \mu \mathrm{M}$ PX-12. At $24 \mathrm{~h}$ after the incubation time was completed, total cells, including floating cells, were then washed with phosphate-buffered saline (PBS) and fixed in $70 \%(\mathrm{v} / \mathrm{v})$ ethanol. The washing step was repeated again with PBS, and then staining with $50 \mathrm{mg} / \mathrm{l} \mathrm{PI}$ which contained $0.1 \%$ Triton X-100 and RNase (100 mg/l) was carried out. Cellular DNA content was measured using a FACSCalibur flow cytometer and analyzed using ModFit LT 2.0 software (both from Becton-Dickinson, Franklin Lakes, NJ, USA).

Apoptosis assay. For the apoptosis assay, apoptotic cell death was determined by Annexin V-FITC Apoptosis Detection Kit II (BD Pharmingen ${ }^{\mathrm{TM}}$, San Diego, CA, USA) according to the manufacturer's protocols. Briefly, $2 \times 10^{5}$ cells/well were seeded in 6-well plates and treated with $5 \mu \mathrm{M}$ PX-12 for $48 \mathrm{~h}$. After the incubation time was completed, total cells, including floating cells, were washed twice with cold PBS and then resuspended in binding buffer at a density of $1 \times 10^{6}$ cells $/ \mathrm{ml}$. Annexin V-FITC $(5 \mu \mathrm{l})$ and PI $(1 \mu \mathrm{g} / \mathrm{ml})$ were then added, and the cells were analyzed with the FACSCalibur flow cytometer.

Migration and invasion assay. The effect of PX-12 on the migration and invasive abilities of the colorectal cancer cells in vitro was examined using Transwell assays. PX-12 $(1 \mu \mathrm{M})$ which has little effect on cell growth at $24 \mathrm{~h}$ was used to treat the colorectal cancer cells. Migration and invasion assays were performed in Costar Transwell cell culture chamber inserts (Corning Costar Corp., Cambridge, MA, USA) with an $8-\mu \mathrm{m}$ pore size. For the migration assay, a total of $1 \times 10^{5}$ cells were collected and seeded to the upper part of the chamber in $100 \mu \mathrm{l}$ of serum-free medium. Medium with 10\% FBS was added to the bottom chamber as a chemoattractant. Cells were supplemented with PX-12 during the incubation time ( $24 \mathrm{~h}$ at a concentration of $1 \mathrm{mM}$ ). After $24 \mathrm{~h}$, the cells that migrated to the lower surface of the membrane were fixed with $4 \%$ of paraformaldehyde, and stained with $0.1 \%$ of crystal violet. The number of cells that migrated to the lower surface of the membrane was counted in five random selected fields under a microscope at a magnification of $\times 100$. For the invasion assays, the polycarbonate membrane filters were coated with 1:3 diluted Matrigel (BD Biosciences, USA). All experiments were carried out in triplicate.

Reverse transcription (RT)-PCR. Total RNA was extracted from cells using TRIzol (Invitrogen), and reverse-transcribed into cDNA using a SuperScript II First Strand DNA Synthesis kit (Promega, Madison, WI, USA). The quantification of mRNA levels was performed using SYBR ${ }^{\circledR}$-Green PCR Master Mix and an ABI 7500 Real-Time PCR System (both from Applied Biosystems, Warrington, UK). The sequences of the forward and reverse primers for the NOX1, CDH17, KLF17, S100P, S100A4 and GAPDH genes used in the realtime RT-PCR are listed in Table I. The relative expression of these genes was normalized to that of GAPDH, an endogenous housekeeping gene.

Western blotting. At $24 \mathrm{~h}$ after cells were treated with PX-12 at the concentrations of 0,5 and $10 \mu \mathrm{M}, \sim 2 \times 10^{6}$ cells were homogenized with lysis buffer containing a protease inhibitor cocktail (P8340; Sigma-Aldrich, St. Louis, MO, USA). The protein concentration was determined using the BCA protein assay kit (Qcbio Science \& Technologies Co., Ltd., Shanghai, China). Total proteins (30 $\mu \mathrm{g})$ were electrophoresed on a $12 \%$ SDS-PAGE and transferred onto PVDF membranes. The membranes were then incubated with an appropriate dilution of the primary antibody for $1 \mathrm{~h}$ followed by incubation with the horseradish peroxidase-conjugated secondary antibody (Amersham, Arlington Heights, IL, USA), and visualized using the enhanced chemiluminescence substrate kit (Amersham Biosciences, Inc.). The primary antibodies used in the present study were polyclonal antibodies against S100A4 and actin (80-50; Abcam, Cambridge, UK).

Statistical analysis. The results in the present study are expressed as means \pm SD. Statistical analysis was performed 

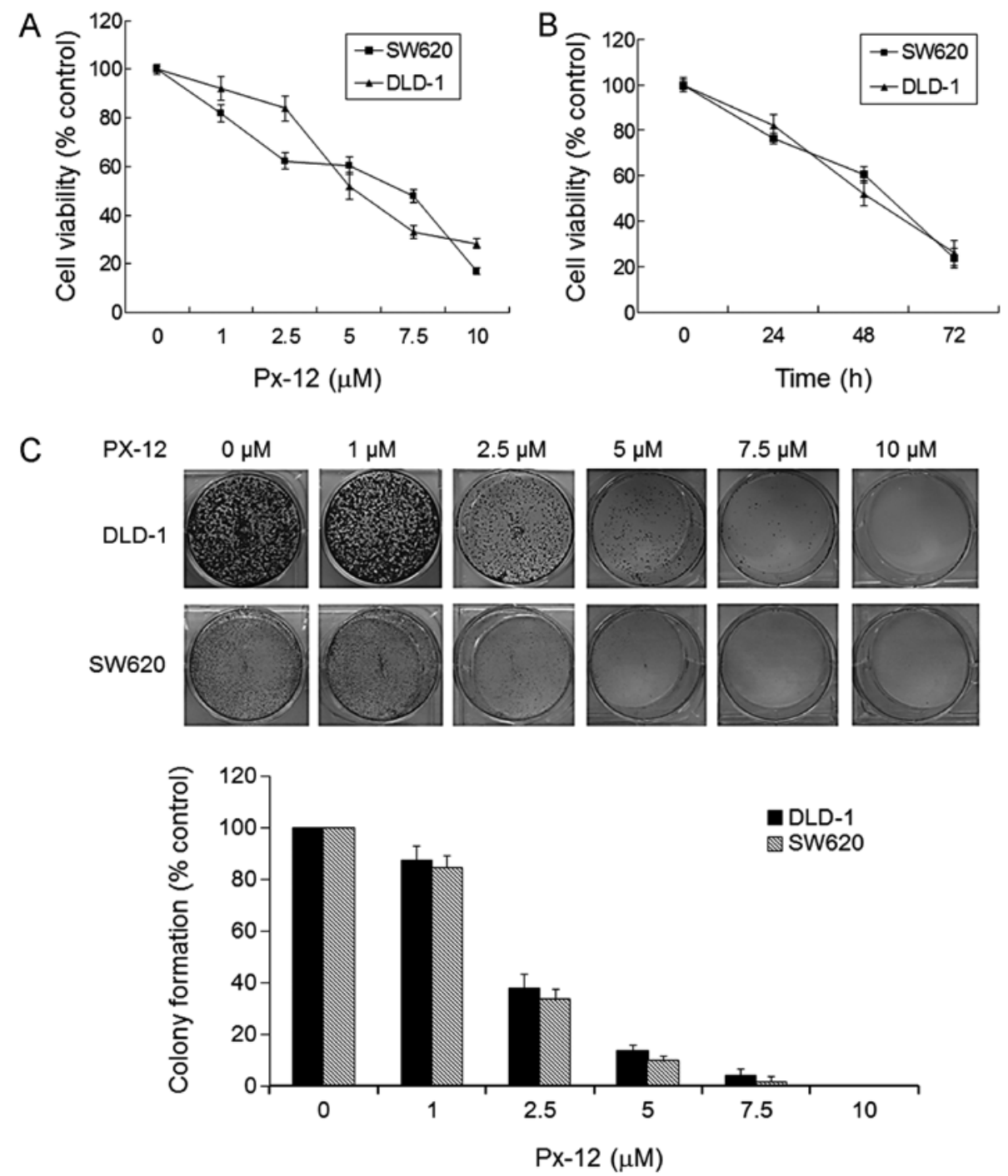

Figure 1. Effects of PX-12 on cell viability and colony formation in colorectal cancer cells. (A) SW620 and DLD-1 cells were treated with PX-12 at the indicated concentrations for $48 \mathrm{~h}$. (B) SW620 and DLD-1 cells were treated with $5 \mu \mathrm{M}$ PX-12 for the indicated time points. (C) Changes in cell colony formation as affected by the indicated concentrations of PX-12 for 14 days; representative images are shown. PX-12, 1-methylpropyl 2-imidazolyl disulfide.

by the independent samples t-test (SPSS, Inc., Chicago, IL, USA). A P-value of $<0.05$ was considered to indicate a statistically significant result.

\section{Results}

PX-12 inhibits colorectal cancer cell proliferation and colony formation. We first examined the effect of PX-12 on the cell viability of human colorectal cancer cell lines DLD-1 and SW620 using an MTT assay. After exposure to a range of concentrations of PX-12 $(0,1,2.5,5,7.5,10 \mu \mathrm{M})$ for $48 \mathrm{~h}$, the viability of the DLD-1 and SW620 cells was reduced in a dose-dependent manner (Fig. 1A). In addition, a time-dependent decrease in cell viability was also observed when cells were treated with $5 \mu \mathrm{M} \mathrm{PX}-12$ (Fig. 1B). As shown in Fig. 1C, DLD-1 and SW620 cells treated with the indicated concentrations of PX-12 for 14 days showed a significant reduction in the colony formation in a dose-dependent manner.

PX-12 alters the cell cycle distribution and induces cell apoptosis in colorectal cancer cells. To evaluate the effects of PX-12 on the cell cycle, cell cycle distributions were determined using flow cytometry. After the indicated PX-12 treatments for $24 \mathrm{~h}, \mathrm{PX}-12$ significantly induced $\mathrm{G} 2 / \mathrm{M}$ phase arrest of the DLD-1 and SW620 cells (Fig. 2). Cell apoptosis was detected by Annexin V-FITC/PI staining. We found that PX-12 induced DLD-1 and SW620 cell apoptosis in a dose-dependent manner (Fig. 3A and B). In additional, PX-12 increased the levels of activated caspase-3 expression in the SW620 and DLD-1 cells at the concentration of $10 \mu \mathrm{M}$ PX-12 for $48 \mathrm{~h}$ (Fig. 3C and D).

PX-12 inhibits colorectal cancer cell migration and invasion. The effects of PX-12 on the migration and invasion of the colorectal cancer cells were evaluated using Transwell filter membrane chambers. PX-12 $(1 \mu \mathrm{M})$, a dose with no significant effect on the rate of apoptosis, was used in the migration and invasion study. As shown by the representative images in Fig. 4A and B, the migration and invasion abilities were inhibited in the PX-12-treated colorectal cancer DLD-1 and SW620 cells. PX-12 treatment of the DLD-1 and SW620 cells decreased the cell counts in the migration assay by 78 and $83 \%$ respectively, and in the invasion assay by 72 and $98.6 \%$, respectively. 

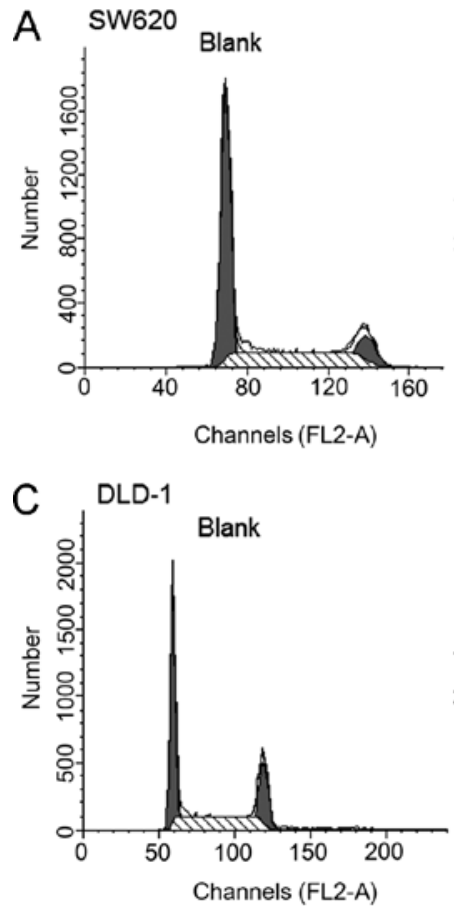
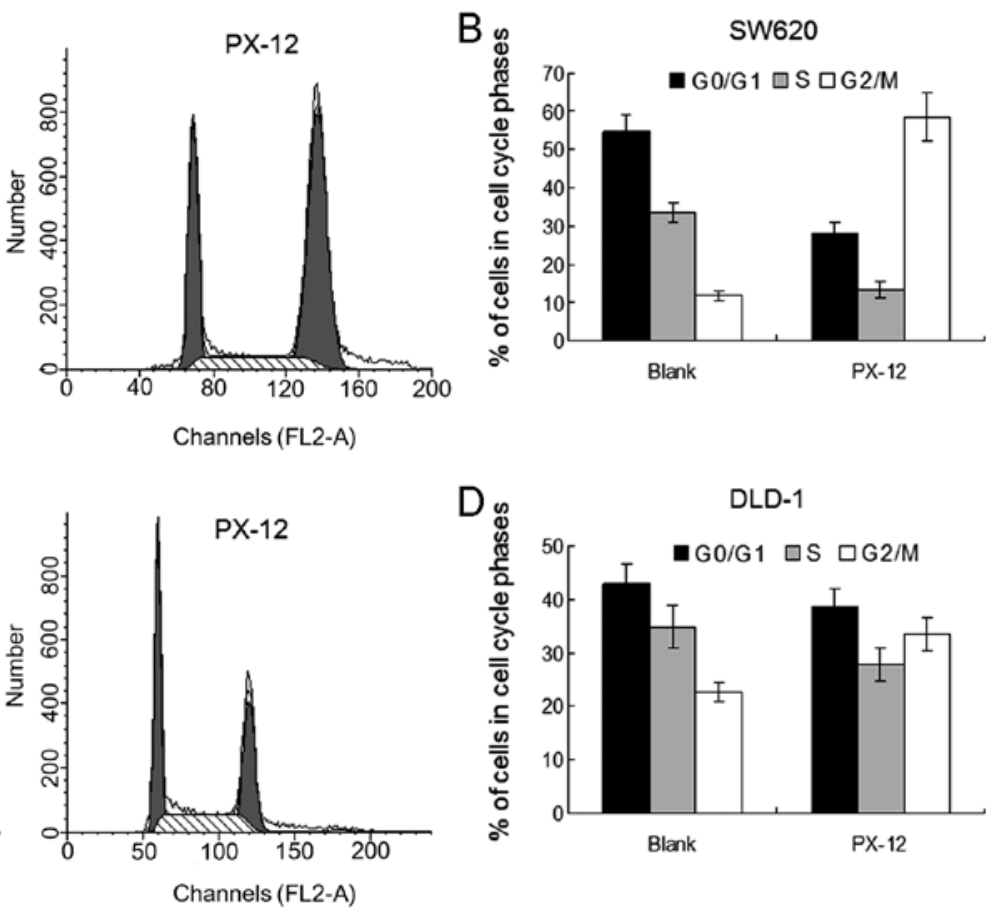

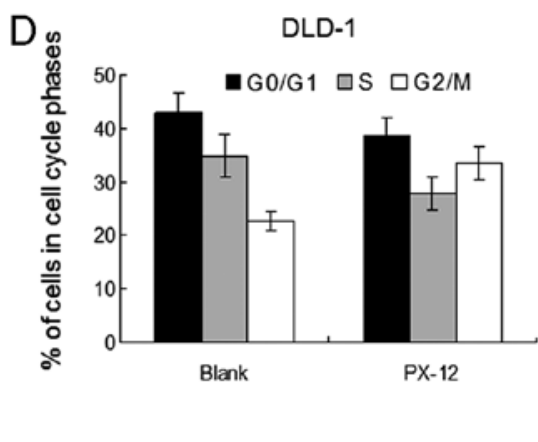

Figure 2. PX-12 alters the cell cycle distribution in SW620 and DLD-1 colorectal cancer cells. (A and C) Representatives results are shown for the SW620 and DLD-1 cells treated with $5 \mu \mathrm{M}$ PX-12 for $48 \mathrm{~h}$. (B and D) After treatment with the indicated concentrations of PX-12 for $48 \mathrm{~h}$, cell cycle distribution was analyzed using flow cytometry. Each value represents the mean \pm SD of three independent experiments. PX-12, 1-methylpropyl 2-imidazolyl disulfide.

A

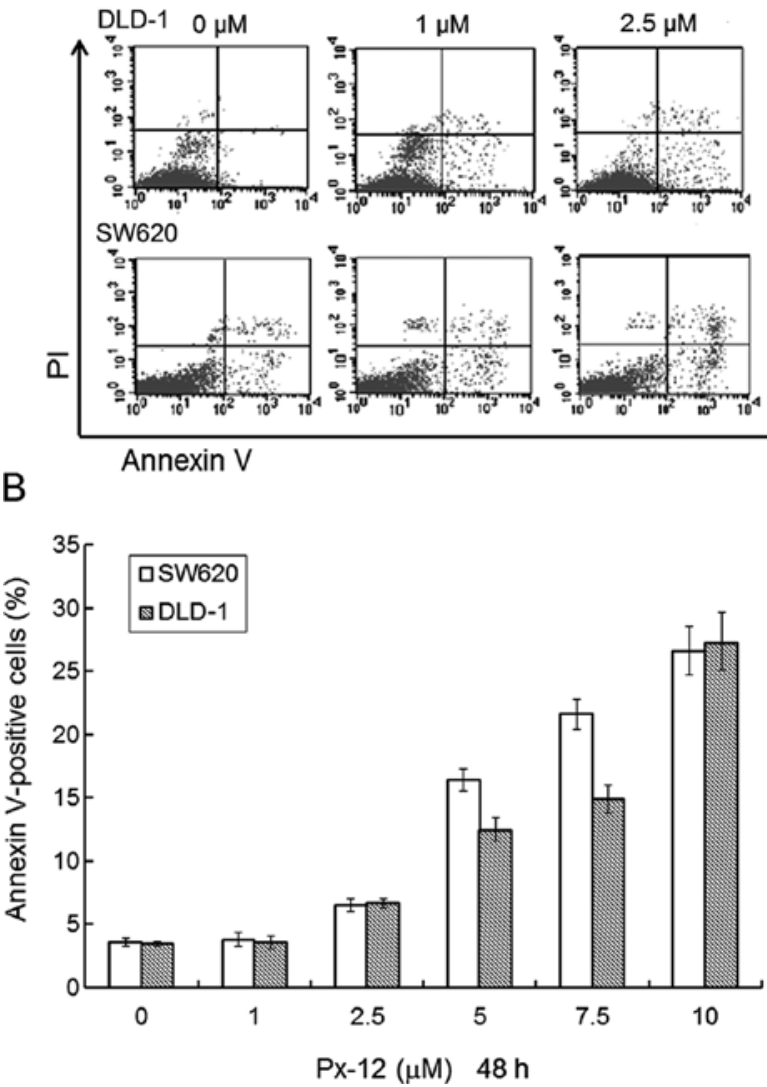

$\mathrm{PX}-12$
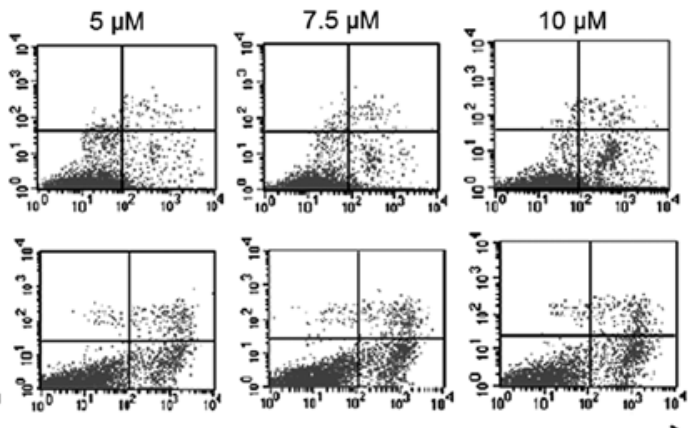

C
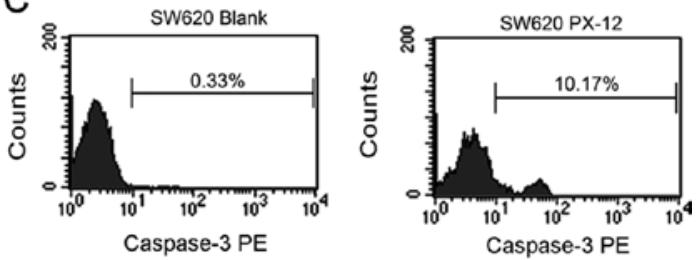

D
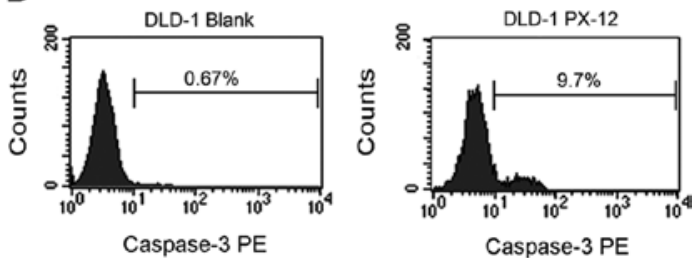

Figure 3. PX-12 induces colorectal cancer cell apoptosis. DLD-1 and SW620 cells were treated with various concentrations of PX-12 for 48 h, and cell apoptosis was detected by Annexin V-FITC/PI staining. (A) Representative results are shown for the DLD-1 and SW620 cells treated with various concentrations of PX-12 for $48 \mathrm{~h}$. (B) The percentage of Annexin V-positive cells was calculated $48 \mathrm{~h}$ after treatment with increasing concentrations of PX-12 (1-10 $\mu \mathrm{M})$. Data are presented as the mean \pm SD of three independent experiments. (C) SW620 cells were treated with $10 \mu \mathrm{M}$ PX-12 for $48 \mathrm{~h}$, and the level of caspase-3 expression was detected using flow cytometry. (D) DLD-1 cells were treated with $10 \mu \mathrm{M}$ PX-12 for $48 \mathrm{~h}$, and the level of caspase-3 expression was detected using flow cytometry. PX-12, 1-methylpropyl 2-imidazolyl disulfide. 

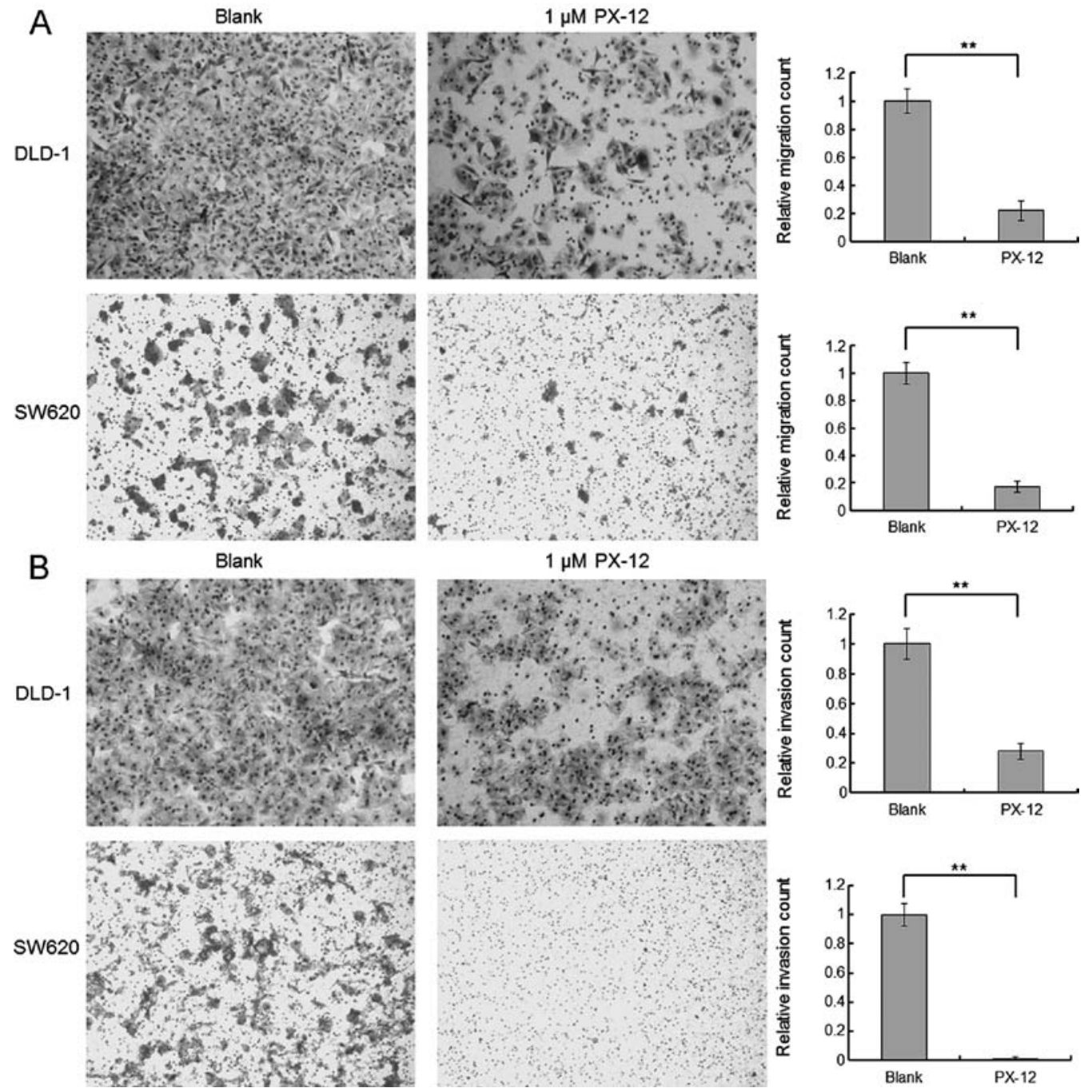

Figure 4. PX-12 inhibits colorectal cancer cell migration and invasion. (A) PX-12 inhibited DLD-1 and SW620 cell migration. (B) PX-12 inhibited DLD-1 and SW620 cell invasion; representative images are shown and the relative migration count of cells was calculated. Microphotographs were captured with magnification, $\mathrm{x} 100 .{ }^{* *} \mathrm{P}<0.01$. PX-12, 1-methylpropyl 2-imidazolyl disulfide.
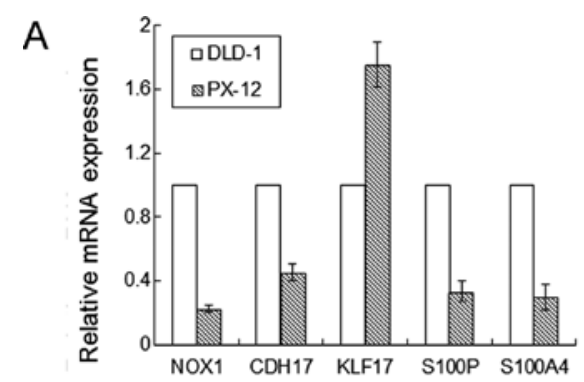

B

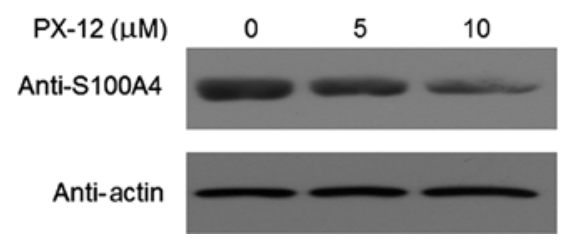

Figure 5. Effects of PX-12 on NOX1, CDH17, KLF17, S100P and S100A4 mRNA expression in colorectal cancer cells. (A) Alteration of the expression of several genes in the PX-12-treated colorectal cancer cells. (B) Western blot analysis of S100A4 protein in the PX-12-treated SW620 cells. PX-12, 1-methylpropyl 2-imidazolyl disulfide. 
SW620 cells, real-time PCR analysis was performed. As shown in Fig. 5A, levels of NOX1, CDH17, S100P and S100A4 mRNA expression were reduced by $>50 \%$, and KLF17 mRNA expression was increased after treatment with $2.5 \mu \mathrm{M}$ PX-12 for $48 \mathrm{~h}$ in the DLD-1 cells. In another colorectal cancer cell line SW620, most of the results were similar as those in the DLD-1 cells except for S100P mRNA expression which had no significance change after treatment with PX-12.

PX-12 decreases S100A4 protein expression in colorectal cancer cells. To examine the effect of PX-12 on S100A4 protein in colorectal cancer cells, western blot analysis was performed. As shown in Fig. 5B, the S100A4 protein expression was diminished as the concentration of PX-12 increased in the SW620 cells.

\section{Discussion}

The differentiation and proliferation of colorectal cancer cells are complex events and the relevant mechanisms have been universally investigated (21-23). Trx-1 expression was reported to be increased in several types of human cancers, including colorectal carcinoma $(10,24)$. Trx-1 has various biological activities, such as antioxidant, growth control, antiapoptotic properties and inflammation regulation that provide reducing equivalents and a transcriptional regulator $(6,25,26)$. PX-12, an inhibitor of Trx-1, has shown excellent in vitro antitumor activity, and Ramanathan et al reported the firstin-human phase I trial of PX-12 in patients with advanced solid tumors (20). However, the antitumor effect of PX-12 in colorectal cancer cells, particularly the effect of PX-12 on cancer cell migration and invasion, is still obscure.

The aim of the present study was to assess the effects of PX-12 on colorectal cancer cells in vitro. Following exposure to a range of concentrations of PX-12 $(0,1,2.5,5,7.5$ and $10 \mu \mathrm{M})$ for $48 \mathrm{~h}$, cell growth was inhibited as the concentration of PX-12 increased. The same result was shown when the exposure time was prolonged. We also demonstrated that PX-12 inhibited colorectal cancer cell colony formation. The susceptibility of colorectal cancer cells to PX-12 appeared to significantly increase after the incubation time was prolonged or the concentration of PX-12 was increased. Namely the inhibitory effects of PX-12 on colorectal cancer cells were dose- and time-dependent. DNA flow cytometric analysis indicated that PX-12 significantly induced G2/M phase arrest of the cell cycle in colorectal cancer DLD-1 and SW620 cells. Similarly, PX-12 induced G2/M phase arrest in breast cancer and lung cancer cells $(27,28)$. Therefore, this body of evidence suggests that the G2/M phase arrest in PX-12-treated cells is an underlying mechanism to suppress the growth of cancer cells, including colorectal cancer cells.

In the apoptosis assay, PX-12 also increased the number of Annexin V-positive cells at the designated concentrations of PX-12 for $48 \mathrm{~h}$, suggesting that PX-12-induced colorectal cancer cell death occurred via apoptosis. Our results indicated that PX-12 induced apoptosis in human colorectal cancer cells through enhancement of caspase-3 activation. In additional, the migration and invasion abilities were inhibited in the PX-12-treated colorectal cancer cells. To further elucidate the molecular mechanisms of the antitumor effects of PX-12, we performed gene array studies and comparative gene profiling analysis of DLD-1 cells treated with PX-12 (data not shown). NOX1, CDH17, KLF17, S100P and S100A4 were found to be regulated by PX-12 in the DLD-1 cells. NOX1, an NADPH oxidase, which is known to enhance reactive oxygen species (ROS), is expressed in all types of tissues including osteoclasts, vascular smooth muscle, and normal gastric and colonic mucosa (29); there is growing evidence that Nox1 is overexpressed in many human colonic adenocarcinomas (30). $\mathrm{CDH} 17$ was found to increase cell adhesion and proliferation in colon cancer cells, by regulating $\alpha 2 \beta 1$ integrin signaling to induce particular focal adhesion kinase and Ras activation (31). KLF17 plays vital roles in many oncogenic processes, such as tumor growth and metastasis. Studies have reported that KLF17 acts as an inhibitor of epithelial-to-mesenchymal transition and metastasis in breast cancer (32). More and more evidence suggests that S100P plays a critical role in tumors. This gene was found to been expressed in several different types of cancer, including colon, pancreas, breast and lung cancer (33-36). Recent studies have also shown that S100A4, a small $\mathrm{Ca}^{2+}$ binding protein, is highly expressed in different tumor tissues (37). High S100A4 expression is related to increased metastasis formation in tumors (38), including colorectal cancer $(39,40)$. We further confirmed a change in the expression of genes by quantitative RT-PCR. After exposure of DLD-1 and SW620 cells to PX-12 for $48 \mathrm{~h}$, NOX1, CDH17 and S100A4 mRNA expression was reduced, while KLF17 mRNA expression was increased. This indicated that PX-12 may trigger the inhibition of NOX1, CDH17 and S100A4 mRNA expression and an increase in KLF17 mRNA expression. S100A4 is overexpressed in a range of different tumor types, and plays an important role in the process of cancer metastasis $(38,41)$. S100A4 expression is significantly associated with positive lymph node metastasis in colorectal cancer (39), and targeting the expression of S100A4 with calcimycin was found to inhibit colon cancer cell migration and invasion $(42,43)$. As shown in Fig. 5B, the S100A4 protein expression was diminished in the PX-12-treated SW620 cells. The mechanism involved in the decrease in S100A4 protein by PX-12 is not known. It is known that PX-12 is an inhibitor of Trx-1 and has antitumor activity. One may predict that inhibition of the Trx-1 redox system leads to decreased S100A4 protein and trans-activation of downstream targets. Therefore, future research is required to investigate the correlation of the antitumor effect of PX-12 on colorectal cancer cells with NOX1, CDH17, S100A4, S100P and KLF17 expression.

In summary, we demonstrated that PX-12 inhibited the growth of colorectal cancer cells via G2/M phase arrest and induction of apoptosis. Notably, a low dose of PX-12 inhibited colorectal cancer cell migration and invasion. PX-12 has been shown to have significant antitumor activity in colorectal cancer in vitro. This antitumor effect may be associated with NOX1, CDH17, S100A4 and KLF17 mRNA expression. The present study provides important insight into the antitumor effects of PX-12 on colorectal cancer cells and represents a novel and effective strategy for treating cancer.

\section{Acknowledgements}

This study was supported by the National Natural Science Foundation of China (81101823), the Medicine and Health 
Technology Program of Zhejiang Province (2013KYA129), and the Wenzhou Science and Technology Bureau Program (Y20120181).

\section{References}

1. Khuhaprema $\mathrm{T}$ and Srivatanakul P: Colon and rectum cancer in Thailand: an overview. Jpn J Clin Oncol 38: 237-243, 2008.

2. Moertel CG, Fleming TR, Macdonald JS, et al: Fluorouracil plus levamisole as effective adjuvant therapy after resection of stage III colon carcinoma: a final report. Ann Intern Med 122: 321-326, 1995.

3. Sargent D, Sobrero A, Grothey A, et al: Evidence for cure by adjuvant therapy in colon cancer: observations based on individual patient data from 20,898 patients on 18 randomized trials. J Clin Oncol 27: 872-877, 2009.

4. Chau I and Cunningham D: Adjuvant therapy in colon cancer what, when and how? Ann Oncol 17: 1347-1359, 2006.

5. Chung-Faye GA and Kerr DJ: ABC of colorectal cancer: innovative treatment for colon cancer. BMJ 321: 1397-1399, 2000.

6. Powis G and Montfort WR: Properties and biological activities of thioredoxins. Annu Rev Biophys Biomol Struct 30: 421-455, 2001.

7. Lim JY, Yoon SO, Hong SW, Kim JW, Choi SH and Cho JY: Thioredoxin and thioredoxin-interacting protein as prognostic markers for gastric cancer recurrence. World J Gastroenterol 18 : 5581-5588, 2012.

8. Powis G and Montfort WR: Properties and biological activities of thioredoxins. Annu Rev Pharmacol Toxicol 41: 261-295, 2001

9. Nakamura H, Bai J, Nishinaka Y, et al: Expression of thioredoxin and glutaredoxin, redox-regulating proteins, in pancreatic cancer. Cancer Detect Prev 24: 53-60, 2000.

10. Raffel J, Bhattacharyya AK, Gallegos A, et al: Increased expression of thioredoxin-1 in human colorectal cancer is associated with decreased patient survival. J Lab Clin Med 142: 46-51, 2003.

11. Ueno M, Masutani H, Arai RJ, et al: Thioredoxin-dependent redox regulation of p53-mediated p21 activation. J Biol Chem 274: 35809-35815, 1999.

12. Welsh SJ, Bellamy WT, Briehl MM and Powis G: The redox protein thioredoxin-1 $(\operatorname{Tr} x-1)$ increases hypoxia-inducible factor $1 \alpha$ protein expression: Trx-1 overexpression results in increased vascular endothelial growth factor production and enhanced tumor angiogenesis. Cancer Res 62: 5089-5095, 2002.

13. Abate C, Patel L, Rauscher FJ III and Curran T: Redox regulation of fos and jun DNA-binding activity in vitro. Science 249: $1157-1161,1990$

14. Kakolyris S, Giatromanolaki A, Koukourakis M, et al: Thioredoxin expression is associated with lymph node status and prognosis in early operable non-small cell lung cancer. Clin Cancer Res 7: 3087-3091, 2001.

15. Grogan TM, Fenoglio-Prieser C, Zeheb R, et al: Thioredoxin, a putative oncogene product, is overexpressed in gastric carcinoma and associated with increased proliferation and increased cell survival. Hum Pathol 31: 475-481, 2000.

16. Jordan BF, Runquist M, Raghunand $\mathrm{N}$, et al: The thioredoxin-1 inhibitor 1-methylpropyl 2-imidazolyl disulfide (PX-12) decreases vascular permeability in tumor xenografts monitored by dynamic contrast enhanced magnetic resonance imaging. Clin Cancer Res 11: 529-536, 2005.

17. Gallegos A, Gasdaska JR, Taylor CW, et al: Transfection with human thioredoxin increases cell proliferation and a dominantnegative mutant thioredoxin reverses the transformed phenotype of human breast cancer cells. Cancer Res 56: 5765-5770, 1996.

18. Wipf P, Hopkins TD, Jung JK, et al: New inhibitors of the thioredoxin-thioredoxin reductase system based on a naphthoquinone spiroketal natural product lead. Bioorg Med Chem Lett 11: 2637-2641, 2001.

19. Kirkpatrick DL, Kuperus M, Dowdeswell M, et al: Mechanisms of inhibition of the thioredoxin growth factor system by antitumor 2-imidazolyl disulfides. Biochem Pharmacol 55: 987-994, 1998.

20. Ramanathan RK, Kirkpatrick DL, Belani CP, et al: A phase I pharmacokinetic and pharmacodynamic study of PX-12, a novel inhibitor of thioredoxin-1, in patients with advanced solid tumors. Clin Cancer Res 13: 2109-2114, 2007.

21. Uchiyama S, Itoh H, Naganuma S, et al: Enhanced expression of hepatocyte growth factor activator inhibitor type 2-related small peptide at the invasive front of colon cancers. Gut 56: 215-226, 2007.
22. Yamazaki K, Shimizu M, Okuno M, et al: Synergistic effects of RXR $\alpha$ and PPAR $\gamma$ ligands to inhibit growth in human colon cancer cells - phosphorylated RXR $\alpha$ is a critical target for colon cancer management. Gut 56: 1557-1563, 2007.

23. Shen D, Deng $C$ and Zhang M: Peroxisome proliferator-activated receptor $\gamma$ agonists inhibit the proliferation and invasion of human colon cancer cells. Postgrad Med J 83: 414-419, 2007.

24. Noike T, Miwa S, Soeda J, Kobayashi A and Miyagawa S: Increased expression of thioredoxin-1, vascular endothelial growth factor, and redox factor-1 is associated with poor prognosis in patients with liver metastasis from colorectal cancer. Hum Pathol 39: 201-208, 2008.

25. Lillig $\mathrm{CH}$ and Holmgren A: Thioredoxin and related molecules - from biology to health and disease. Antioxid Redox Signal 9: 25-47, 2007.

26. Arnér ES: Focus on mammalian thioredoxin reductases important selenoproteins with versatile functions. Biochim Biophys Acta 1790: 495-526, 2009.

27. Vogt A, Tamura K, Watson S and Lazo JS: Antitumor imidazolyl disulfide IV-2 causes irreversible $\mathrm{G}_{2} / \mathrm{M}$ cell cycle arrest without hyperphosphorylation of cyclin-dependent kinase Cdk1. J Pharmacol Exp Ther 294: 1070-1075, 2000.

28. Shin HR, You BR and Park WH: PX-12-induced HeLa cell death is associated with oxidative stress and GSH depletion. Oncol Lett 6: 1804-1810, 2013

29. Krause KH: Tissue distribution and putative physiological function of NOX family NADPH oxidases. Jpn J Infect Dis 57: S28-S29, 2004.

30. Juhasz A, Ge Y, Markel S, et al: Expression of NADPH oxidase homologues and accessory genes in human cancer cell lines, tumours and adjacent normal tissues. Free Radic Res 43: 523-532, 2009.

31. Bartolomé RA, Barderas R, Torres S, et al: Cadherin-17 interacts with $\alpha 2 \beta 1$ integrin to regulate cell proliferation and adhesion in colorectal cancer cells causing liver metastasis. Oncogene 33: 1658-1669, 2014

32. Gumireddy K, Li A, Gimotty PA, et al: KLF17 is a negative regulator of epithelial-mesenchymal transition and metastasis in breast cancer. Nat Cell Biol 11: 1297-1304, 2009.

33. Fuentes MK, Nigavekar SS, Arumugam T, et al: RAGE activation by $\mathrm{S} 100 \mathrm{P}$ in colon cancer stimulates growth, migration, and cell signaling pathways. Dis Colon Rectum 50: 1230-1240, 2007.

34. Logsdon CD, Simeone DM, Binkley C, et al: Molecular profiling of pancreatic adenocarcinoma and chronic pancreatitis identifies multiple genes differentially regulated in pancreatic cancer. Cancer Res 63: 2649-2657, 2003.

35. Guerreiro Da Silva ID, Hu YF, Russo IH, et al: S100P calcium-binding protein overexpression is associated with immortalization of human breast epithelial cells in vitro and early stages of breast cancer development in vivo. Int $\mathbf{J}$ Oncol 16: 231-240, 2000.

36. Diederichs S, Bulk E, Steffen B, et al: S100 family members and trypsinogens are predictors of distant metastasis and survival in early-stage non-small cell lung cancer. Cancer Res 64: 5564-5569, 2004.

37. Mishra SK, Siddique HR and Saleem M: S100A4 calciumbinding protein is key player in tumor progression and metastasis: preclinical and clinical evidence. Cancer Metastasis Rev 31: 163-172, 2012.

38. Boye K and Maelandsmo GM: SS100A4 and metastasis: a small actor playing many roles. Am J Pathol 176: 528-535, 2010.

39. Huang LY, Xu Y, Cai GX, et al: S100A4 over-expression underlies lymph node metastasis and poor prognosis in colorectal cancer. World J Gastroenterol 17: 69-78, 2011.

40. Stein $U$, Arlt F, Walther W, et al: The metastasis-associated gene S100A4 is a novel target of $\beta$-catenin/T-cell factor signaling in colon cancer. Gastroenterology 131: 1486-1500, 2006.

41. Orre LM, Panizza E, Kaminskyy VO, et al: S100A4 interacts with p53 in the nucleus and promotes p53 degradation. Oncogene 32: 5531-5540, 2013.

42. Sack U, Walther W, Scudiero D, et al: S100A4-induced cell motility and metastasis is restricted by the Wnt/ $\beta$-catenin pathway inhibitor calcimycin in colon cancer cells. Mol Biol Cell 22: 3344-3354, 2011.

43. Jiang L, Lai YK, Zhang J, et al: Targeting S100P inhibits colon cancer growth and metastasis by lentivirus-mediated RNA interference and proteomic analysis. Mol Med 17: 709-716, 2011. 